\title{
IMAGENOLOGÍA EN CORONAVIRUS SARS-COV-2
}

\section{IMAGENOLOGY IN CORONAVIRUS SARS-COV-2}

\section{Alejandra BELLO ${ }^{1}$, María José RODRÍGUEZ ${ }^{1}$.}

${ }^{1}$ Universidad Nacional de Asunción, Facultad de Ciencias Médicas, San Lorenzo, Paraguay.

Cómo citar este artículo: Bello A, Rodríguez MJ. Imagenología en coronavirus SARS-CoV-21. Med. clín. soc. 2019;3(3):100-101.

\section{Estimado Editor,}

Es importante recabar información veraz acerca de lo que potencialmente el coronavirus representa para la población desde el punto de vista clínico, métodos laboratoriales de detección y métodos de imagenología para la identificación oportuna de casos y seguimiento eficaz.

En diciembre de 2019, un grupo de pacientes con neumonía de causa desconocida se había relacionado con un mercado mayorista de mariscos en la localidad de Wuhan, China. Se descubre un betacoronavirus previamente conocido mediante el uso de secuenciación genética, usando las células epiteliales de las vías respiratorias humanas se aísla el nuevo coronavirus, llamado SARS-CoV-2 (1).

En las revisiones realizadas, las pruebas de imágenes utilizadas para la caracterización de neumonías y complicaciones son la radiografía de tórax y tomografía axial computada. En los pacientes con el nuevo coronavirus se realizaron pruebas iniciales de Tomografía de tórax simple con hallazgos anormales (1). Estos hallazgos consisten inicialmente en patrones de neumonía viral bilateral a expensas de consolidación lobar múltiples y segmentarias, opacificaciones en vidrio esmerilado; en el transcurso de los controles realizados se observan mejoras del patrón con persistencia de opacificaciones en vidrio esmerilado con resolución de consolidaciones iniciales (1).

En otra descripción epidemiológica caracterizada por Chen et al (2); de los pacientes estudiados, estos presentaron tos, fiebre, dificultad respiratoria y los hallazgos de imágenes en tomografía en el primer día en la mayoría de su población de estudio muestran una neumonía bilateral y patrón en vidrio esmerilado múltiple, presencia de neumonía bilateral y complicaciones mínimas.

Dado que la epidemia de influenza se ha dado concomitantemente en el territorio chino con la aparición de la neumonía viral por SARS-CoV-2 (1), el hecho de que los hallazgos radiológicos se hayan dado de forma inespecífica debido a falta de un patrón característico que inicie la sospecha de un nuevo patógeno implicado ha contribuido sustancialmente a la no caracterización del nuevo coronavirus.

En países con recursos de salud limitado, el conocimiento clínico y el uso racional de métodos de diagnóstico son vitales para la disminución de gastos innecesarios para el manejo de la 
epidemia, y según la revisión de archivos que se ha realizado, la imagenología es una herramienta importante para el seguimiento e identificación de complicaciones concomitantes y el diagnostico laboratorial por secuenciación para la caracterización inicial del coronavirus (3).

\section{CONFLICTOS DE INTERÉS Y FUENTE DE FINANCIACIÓN}

La autora declara no poseer conflictos de interés. Fuente de financiación: ninguna.

\section{REFERENCIAS BIBLIOGRÁFICAS}

1. Huang C, Wang Y, Li X, Ren L, Zhao J, Hu Y, et al. Clinical features of patients infected with 2019 novel coronavirus in Wuhan, China. The Lancet. 2020;395(10223):497-506. https://doi.org/10.1016/S0140-6736(20)30183-5

2. Chen N, Zhou M, Dong X, Qu J, Gong F, Han Y, et al. Epidemiological and clinical characteristics of 99 cases of 2019 novel coronavirus pneumonia in Wuhan, China: a descriptive study. The Lancet. 2020;395(10223):507-13. https://doi.org/10.1016/S0140-6736(20)30211-7

3. Corman VM, Landt O, Kaiser M, Molenkamp R, Meijer A, Chu DK, et al. Detection of 2019 novel coronavirus (2019-nCoV) by real-time RT-PCR. Euro Surveill. 2020;25(3):2000045. https://dx.doi.org/10.2807\%2F1560-

\section{ES.2020.25.3.2000045}

